\title{
Synthesis of High Porosity, Monolithic Alumina Aerogels
}

\author{
J. F. Poco, J. H. Satcher, Jr., L. W. Hrubesh
}

This article was submitted to $6^{\text {th }}$ International Symposium on Aerogels, Albuquerque, NM., October 8-11, 2000

\section{September 20, 2000}

U.S. Department of Energy

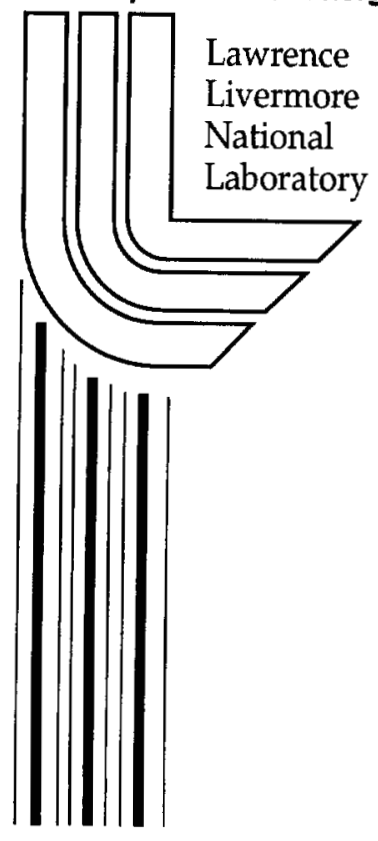




\section{DISCLAIMER}

This document was prepared as an account of work sponsored by an agency of the United States Government. Neither the United States Government nor the University of California nor any of their employees, makes any warranty, express or implied, or assumes any legal liability or responsibility for the accuracy, completeness, or usefulness of any information, apparatus, product, or process disclosed, or represents that its use would not infringe privately owned rights. Reference herein to any specific commercial product, process, or service by trade name, trademark, manufacturer, or otherwise, does not necessarily constitute or imply its endorsement, recommendation, or favoring by the United States Government or the University of California. The views and opinions of authors expressed herein do not necessarily state or reflect those of the United States Government or the University of California, and shall not be used for advertising or product endorsement purposes.

This is a preprint of a paper intended for publication in a journal or proceedings. Since changes may be made before publication, this preprint is made available with the understanding that it will not be cited or reproduced without the permission of the author.

This work was performed under the auspices of the United States Department of Energy by the University of California, Lawrence Livermore National Laboratory under contract No. W-7405-Eng-48.

This report has been reproduced directly from the best available copy.

Available electronically at http://www.doc.gov/bridge

Available for a processing fee to U.S. Department of Energy

And its contractors in paper from

U.S. Department of Energy

Office of Scientific and Technical Information

P.O. Box 62

Oak Ridge, TN 37831-0062

Telephone: (865) 576-8401

Facsimile: (865) 576-5728

E-mail: reports@adonis.osti.gov

Available for the sale to the public from

U.S. Department of Commerce

National Technical Information Service

5285 Port Royal Road

Springfield, VA 22161

Telephone: (800) 553-6847

Facsimile: (703) 605-6900

E-mail: orders@ntis.fedworld.gov

Online ordering: http://www.ntis.gov/ordering.htm

\section{OR}

Lawrence Livermore National Laboratory

Technical Information Department's Digital Library

http://www.llnl.gov/tid/Library.html 


\title{
Synthesis of High Porosity, Monolithic Alumina Aerogels*
}

\author{
J.F. Poco, J.H. Satcher Jr., and L.W. Hrubesh
}

Chemistry and Material Science Department

Lawrence Livermore National Laboratory

Livermore, CA 94550

* This work was performed under the auspices of the U.S. Department of Energy by University of California Lawrence Livermore National Laboratory under contract No. W-7405-Eng-48.

\begin{abstract}
Many non-silica aerogels are notably weak and fragile in monolithic form. Particularly, few monolithic aerogels with densities less than $50 \mathrm{~kg} / \mathrm{m}^{3}$ have any significant strength. It is especially difficult to prepare uncracked monoliths of pure alumina aerogels that are robust and moisture stable. In this paper, we discuss the synthesis of strong, stable, monolithic, high porosity ( $>98 \%$ porous) alumina aerogels, using a two-step sol-gel process. The alumina aerogels have a polycrystalline morphology that results in enhanced physical properties. Most of the measured physical properties of the alumina aerogels are superior to those for silica aerogels for equivalent densities.
\end{abstract}

\section{Introduction}

Alumina-based ceramics, in addition to their relatively high strength, are noted for their enhanced thermal and chemical stability. These properties of alumina have been shown to also apply to low density aerogel materials. To date, the major use for alumina-based aerogels is as high temperature, high surface area catalyst supports. Monolithic alumina aerogels, which have been difficult to produce by current synthetic procedures, would be capable of providing thermal insulation over a larger temperature range than the more common silica aerogels and would be a useful material for many applications. For example, monolithic alumina aerogel crucibles could be used for improved high temperature alloy melt processing. In this paper we report a new synthetic procedure for preparing monolithic, high porosity, alumina 
aerogels. These aerogels have an unusual polycrystalline microstructure, and a very low thermal conductivity of $98 \mathrm{~mW} / \mathrm{mK}$ at $800^{\circ} \mathrm{C}$ and $1 \mathrm{~atm}$.

The sol-gel synthesis of alumina gels has been well studied and it has been found that the complex solution chemistry of aluminum hydroxide complicates the structural formation of the gel. Yoldas [1-5] and Teichner [6] have shown that there are several possible structural variations in the aluminum alkoxide derived gels. Some of the variables that affect the final structure of the gel include; the type of alkoxide used, the ratio of alkoxide to water, the rate of hydrolysis, the temperature of drying, the type of catalyst used, the $\mathrm{pH}$ of the solution, and the temperature at which the reactions occur. The final form of the aerogel may be monolithic or powder, amorphous or crystalline, or bi-phasic, heterogenous or homogenous.

Considerable work has been published for both pure alumina aerogels [7-11] and composite alumina-silica aerogels [11-17]. The synthesis of monolithic, stable, high porosity alumina aerogels has been found to be especially difficult due to the complex chemical pathways leading to gelation, the susceptability to cracking during drying, and the hygroscopic nature of the dried material. Only a few papers describe the formation of truly monolithic aerogels containing alumina $[7,9,10,15,17]$, and the highest porosity, pure alumina aerogel reported was $\sim 95 \%$ porous [9].

Our primary motivation to develop very high porosity ( $>98 \%$ porous) monolithic alumina aerogels is for space applications. Thermal protection is needed for space vehicles and thermal insulation is required for many of the experiment assemblies. Monolithic alumina aerogels could be used separately or they could be added to other thermal protection materials to make composites with superior thermal resistance properties. For space applications, lightweight is the most important requirement, thermal resistance is next, and finally robustness and stability. The procedure described here produces monolithic aerogels that exhibit all of these important features.

\section{Experimental procedure}

\subsection{Aerogel preparation}

The monolithic gels are made in two steps; first an alumina sol is made, then the sol is gelled in the second step. The alumina sol is made following a variation of Yoldas' procedure [2], using less than the stoichiometric amount 
of water instead of a large water excess. Our procedure is similar to the one reported by Himmel, et al [11], with some variations in the chemistry and the drying. The chemicals for the preparation are as follows: aluminum tri-sec butoxide $97 \%$ from Aldrich, ethanol-absolute (200 proof) from AAPER, acetic acid (glacial) from EM Sciences, and methanol ACS Grade 99.8\% from Aldrich. In the first step, a sol is made by mixing aluminum secondary butoxide, 200 proof ethanol and $\mathrm{DI}$ water in a molar ratio of $\left\{\mathrm{Al}(\mathrm{sec}-\mathrm{OBu})_{3}\right.$ : EtOH $\left.: \mathrm{H}_{2} \mathrm{O}=1: 16: 0.6\right\}$, and heating to $60^{\circ} \mathrm{C}$ while stirring for 45 minutes. The mixture is initially cloudy but it turns clear after the onset of hydrolysis. The clear sol solution is then cooled to room temperature. In the second step, the gel is made by mixing a portion of the sol solution with methanol, water, and acetic acid. The amounts for this mixture are determined by the targeted porosity of the final aerogel. For example, for a targeted porosity of $98.5 \%$, the weight ratio is $\left\{\mathrm{Sol}: \mathrm{MeOH}: \mathrm{H}_{2} \mathrm{O}=1 \mathrm{~g}\right.$ : $0.2 \mathrm{~g}: 0.003 \mathrm{~g}$ \} and the amount of acetic acid is $1 \mathrm{ml}$ for each $30 \mathrm{ml}$ of the mixture. The mixture is stirred for 30 minutes, then poured into molds where the gel typically forms within 120 minutes.

The gels are dried by supercritical extraction (SCE) of methanol, in an autoclave at $300^{\circ} \mathrm{C}$ and $12.2 \mathrm{MPa}$ pressure. The autoclave is evacuated after decompression, while cooling.

\subsection{Characterization}

Scanning electron micrographs (SEM) were obtained on uncoated specimens using a Hitachi S-800 instrument. The dry aerogel was analyzed with $20 \mathrm{kv}$ beam voltage for a sufficiently short time to limit charging of the sample. High resolution transmission electron micrographs (HRTEM) were obtained on a Philips CM300 FEG instrument, operating at $300 \mathrm{kV}$. Flecks from the dry sample were dropped onto a holey carbon film and analyzed directly.

The thermal conductivity was measured with a heat flux-meter operating in a temperature range of $30-50^{\circ} \mathrm{C}$. This non-commercial instrument was calibrated using NIST traceable standards. The high temperature thermal conductivity measurements were made by Energy Materials Testing Laboratory, Biddeford, Maine, using a guarded hot plate apparatus, according to the ASTM C 177 procedure.

Sound velocity measurements were made using a Panametrics Ultrasonic Analyzer Model $5052 \mathrm{UA}$ with $180 \mathrm{kHz}$ center frequency transducers. The monolithic aerogel specimens were prepared with flat, parallel surfaces, with $1.5 \mathrm{~cm}$ thickness. The elastic modulus of the aerogels was calculated from the 
densities and the measured longitudinal and shear sound velocities, according to the procedures reported by Gross, et al [18].

Surface area measurements were made on a Micromeritics L3000 Analyzer, using the BET nitrogen adsorption/desorption technique.

\section{Results}

The unusual morphology of the SCE dried alumina aerogel is shown in the SEM (figure 1) and HRTEM (figures 2 and 3) micrographs. Electron diffraction of the aerogel (the insert in figure 3) shows distinct ring patterns indicating an ordered structure. The alumina aerogel exhibits a polycrystalline morphology which can be seen as randomly oriented patches of ordered planes in the HRTEM, figure 3 . The microstructure consists of randomly connected acicular, leaf-like particles, quite different from the typical morphology of colloidal, amorphous aerogel that consists of interconnected spheroidal particles.

The measured thermal conductivity values at $1 \mathrm{~atm}$. pressure for the alumina aerogel are $0.029 \mathrm{~W} / \mathrm{mK}$ at $30^{\circ} \mathrm{C}, 0.058 \mathrm{~W} / \mathrm{mK}$ at $400^{\circ} \mathrm{C}$, and 0.098 at $800^{\circ} \mathrm{C}$. These values are compared in Table 1 with values for silica aerogels of the same nominal density, made by two separate methods, base catalyzed (BC) [19] and two step acid/base catalyzed (ABC) [20]. The thermal resistance of the alumina aerogel is clearly superior to the silica aerogels at elevated temperatures.

Unlike the silica aerogels that shrink at temperatures as low as $600^{\circ} \mathrm{C}$, the monolithic alumina aerogels do not sinter until $>950^{\circ} \mathrm{C}$. Several monoliths of the alumina aerogel were heated in a furnace at $1050^{\circ} \mathrm{C}$ for 4 hours, then cooled to room temperature. The dimensions were measured before and after the heat treatment. The change in the linear dimensions for the monoliths were less than $2 \%$. This result is consistent with similar results for aluminumsilicate aerogel compositions that have high alumina content [16].

The isotherm plot for nitrogen adsorption/desorption on the alumina aerogel is a Type II. The specific surface area determined from the desorption curve is $376 \mathrm{~m}^{2} / \mathrm{g}$. The specific surface areas of several types of aerogels are compared in Table 1. The relatively low value for alumina aerogel is attributed to the leaf-like morphology, compared with the colloidal morphology for high porosity silica aerogels. 
The elastic modulus of the alumina aerogel $(550 \mathrm{KPa})$ is determined from the measured longitudinal $(158 \mathrm{~m} / \mathrm{s})$ and shear $(87 \mathrm{~m} / \mathrm{s})$ sound velocities. As can be seen in Table 1 , the elastic modulus of the very high porosity alumina aerogel is higher than for silica aerogels having the same nominal density.

Table 1. Some measured properties of high porosity alumina and silica aerogels.

\begin{tabular}{|c|c|c|c|c|c|c|}
\hline \multirow[t]{2}{*}{$\begin{array}{l}\text { Aerogel } \\
\text { Type }\end{array}$} & \multirow[t]{2}{*}{$\begin{array}{l}\text { Density } \\
\mathrm{Kg} / \mathrm{m}^{3}\end{array}$} & \multirow[t]{2}{*}{$\begin{array}{l}\text { Elastic Modulus } \\
\quad(\mathrm{KPa})\end{array}$} & \multicolumn{3}{|c|}{$\begin{array}{l}\text { ThermalConductivity } \\
(m \mathrm{~W} / \mathrm{mK}) @ \mathrm{P}=1 \mathrm{~atm} .\end{array}$} & \multirow[t]{2}{*}{$\begin{array}{l}\text { Specific Surface Area } \\
\qquad\left(\mathrm{m}^{2} / \mathrm{g}\right)\end{array}$} \\
\hline & & & $30^{\circ} \mathrm{C}$ & $400^{\circ}$ & $800^{\circ} \mathrm{C}$ & \\
\hline Alumina & 37 & 550 & 29 & 58 & 98 & 376 \\
\hline Silica (BC) & 40 & 434 & 31 & 122 & ---- & 574 \\
\hline Silica (ABC) & ) 39 & 489 & 33 & 106 & ---- & 649 \\
\hline
\end{tabular}

\section{Discussion}

The alumina aerogels produced by this procedure are mostly crystalline, in contrast with most common aerogels, which are mostly amorphous. Some crystallinity of the alumina aerogel is expected based on the observation by others of the sol-gel formation in aluminum alkoxide systems. Yoldas' method to make sols at elevated temperatures is known to produce particles with the boehmite phase [2]. Also, it is known that supercritically drying the gels at high temperature can convert the gels to the boehmite phase and the degree of conversion of the pseudoboehmite phase depends on the time held at temperature in the autoclave [7]. Mizushima and Hori observed the formation of boehmite 'fibrils' in aerogels that were dried at $270^{\circ} \mathrm{C}$ in an autoclave [9]. This crystalline form prevented sintering until higher temperatures and caused strengthening of the alumina aerogels. In addition, it is reported that the degree of crystallinity in pure alumina aerogels depends on the alcohol used as a solvent $[7,14]$.

The transmission electron diffraction data from the alumina aerogel shows peaks that do not match either the boehmite or bayerite phase for alumina. We have not made measurements to determine the crystal composition. It is possible that the crystal structure matches that of $\mathrm{Al}(\mathrm{OEt})_{3}$ as was proposed by Himmel, et al, [11] for gel preparations similar to ours. They also observed flat, disc-like regions in their alumina aerogels, which appear to be similar to the leaf-like character for our alumina aerogels. 
The degree of crystallinity of the aerogel produced by our procedure is very high; estimated from the HRTEM images to be $>90 \%$. We believe that this is due to a combination of effects. We use a substoichiometric amount of water and no acid is added in the first step. We used acetic acid in the second step, which releases water with reactions with alcohol and allows control of the hydrolysis rates [21]. Finally, we carry out the supercritical extraction in an autoclave at elevated temperature and pressure.

While the very low density aerogels are all quite fragile materials, the high degree of crystallinity of the structure leads to increased strength of the alumina aerogel. The modulus of the alumina aerogel is $12-26 \%$ higher than silica aerogels having similar density. The crystalline structure and the highly connected, leaf-like morphology are also responsible for the enhanced thermal and mechanical properties. Yoldas [22] points out that the physical properties, such as melting point, viscosity, mechanical behavior and capability of the network to remain monolithic (during drying or consolidation) of the dried gels, depends on high connectivity in the network. The low value for the thermal conductivity measured for the alumina aerogel, is again due to the high degree of connectivity of the gel network.

Our attempts to make low density, monolithic alumina gels using Yoldas' method with large excess water were not successful, either by supercritical drying in $\mathrm{CO} 2$ or by autoclave drying. The gels were either not monolithic as removed from the dryer, or they converted to powder after exposure to atmospheric moisture. The apparent conversion of the gels to bayerite phase could cause the instability to atmospheric moisture [1].

Acetic acid was chosen for the gelation step because its reactions liberate water in alcohol solutions, thus offering a means to control hydrolysiscondensation reaction rates $[11,21]$. Reaction rates are especially critical for the formation of homgeneous gels from highly reactive or partially hydrolyzed alkoxides .

\section{Conclusions}

Very strong, very low density alumina aerogel monoliths can be prepared using a two-step sol-gel process. Our method of preparing pure alumina aerogel, modifies the Yoldas sol method by combining the use of substoichiometric water for hydrolysis, the use of acetic acid to control hydrolysis/condensation, and high temperature supercritical drying. All of 
these procedures contribute to the formation of a polycrystalline aerogel microstructure. This structure is responsible for the exceptional mechanical properties of the alumina aerogel, as well as the enhanced thermal resistance and high temperature stability. The monoliths exhibit excellent insulating and refractory behavior, having low thermal conductivity up to $800^{\circ} \mathrm{C}$ and they do not undergo significant structural changes up to $1050^{\circ} \mathrm{C}$.

\section{Acknowledgements}

We wish to acknowledge the excellent TEM and BET analysis done by Mark Wall and Alexander Gash, respectively. We also thank Thomas Tillotson for his critique of this work.

\section{References}

[1] B.E. Yoldas, J. Appl. Chem. Biotechnol. 23 (1973) 803.

[2] B.E. Yoldas, Am. Ceramic Soc. Bull. , Vol. 54, No. 3 (1975) 286.

[3] B.E. Yoldas, Am. Ceramic Soc. Bull. , Vol. 54, No. 3 (1975) 289.

[4] D.P. Partlow and B.E. Yoldas, J. Non-Crystalline Solids 46 (1981) 153.

[5] B.E. Yoldas, in Chemical Processing of Advanced Materials, ed. L. Hench and J.K West, John Wiley and Sons, Inc. (1992) 60.

[6] S.J. Teichner, Revue De Physique Appliquee, Colloque C4, Supplement 4, April 1989, pp. 22.

[7] Y. Mizushima and M. Hori, J. Mater. Res. 8 (1993) 2993.

[8] Y. Mizushima, M. Hori and M. Saski, J. Mater. Res. 8 (1993) 2109.

[9] Y. Mizushima and M. Hori, J. Non-Crystalline Solids 167 (1994) 1.

[10] T. Horiuchi, T. Osaki, T. Sugiyama, H. Masuda, M. Horio, K. Suzuki, T. Mori, T. Sago, J. Chem. Soc. Faraday Trans. 90 (1994) 2573.

[11] B. Himmel, Th. Gerber, H. Burger, G. Holzhuter, A.Olbertz, J. NonCrystalline Solids 186 (1995) 149. 
[12] F. Chaput, A. Lecomte, A. Dauger and J.P. Boilot, Revue De Physique Appliquee, Colloque C4, Supplement 4, April 1989, pp. 137.

[13] C. Hoang-Van, B. Pommier, R. Harivololona and P. Pichat, J. NonCrystalline Solids 145 (1992) 250.

[14] M.A. Aegerter and D. Bozano, in Chemical Processing of Advanced Materials, ed. L. Hench and J.K West, John Wiley and Sons, Inc. (1992) 175.

[15] S. Komarneni, R. Roy, U. Selvaray, P.B. Malla and E. Breval, J. Mater. Res. 8 (1993) 3163.

[16] R. Saliger, T. Heinrich, T. Gleissner, J. Fricke, J. Non-Crystalline Solids $186(1995) 113$.

[17] T. Osaki, T. Horiuchi, T. Sugiyama, K. Susuki and T. Mori, J. of NonCrystalline Solids (1998) 111.

[18] J. Gross, G. Reichenauer and J. Fricke, J. Phys. D: Appl. Phys. 21 (1988) 1447.

[19] G.A. Nicolaon and S.J. Teichner, Bull. Soc. Chim. F. (1968) 1906.

[20] T.M. Tillotson and L.W. Hrubesh, J. of Non-Crystalline Solids 145 (1992) 44.

[21] J. Livage and C. Sanchez, J. of Non-Crystalline Solids 145 (1992) 11.

[22] B.E. Yoldas, in Chemical Processing of Advanced Materials, ed. L. Hench and J.K West, John Wiley and Sons, Inc. (1992) 60. 


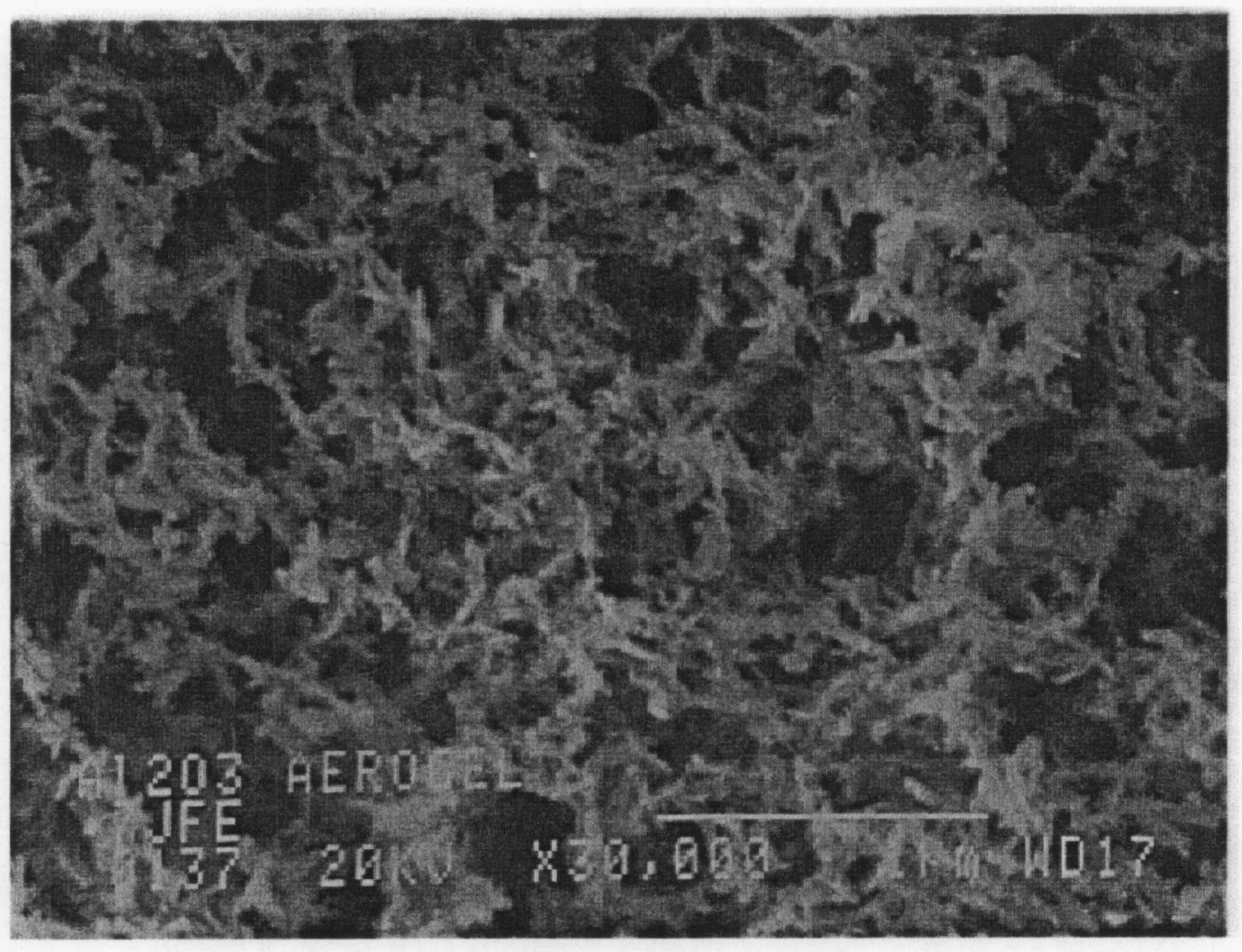

Fig. 1. Scanning electron micrograph of $98.5 \%$ porosity alumina aerogel showing acicular morphology. 


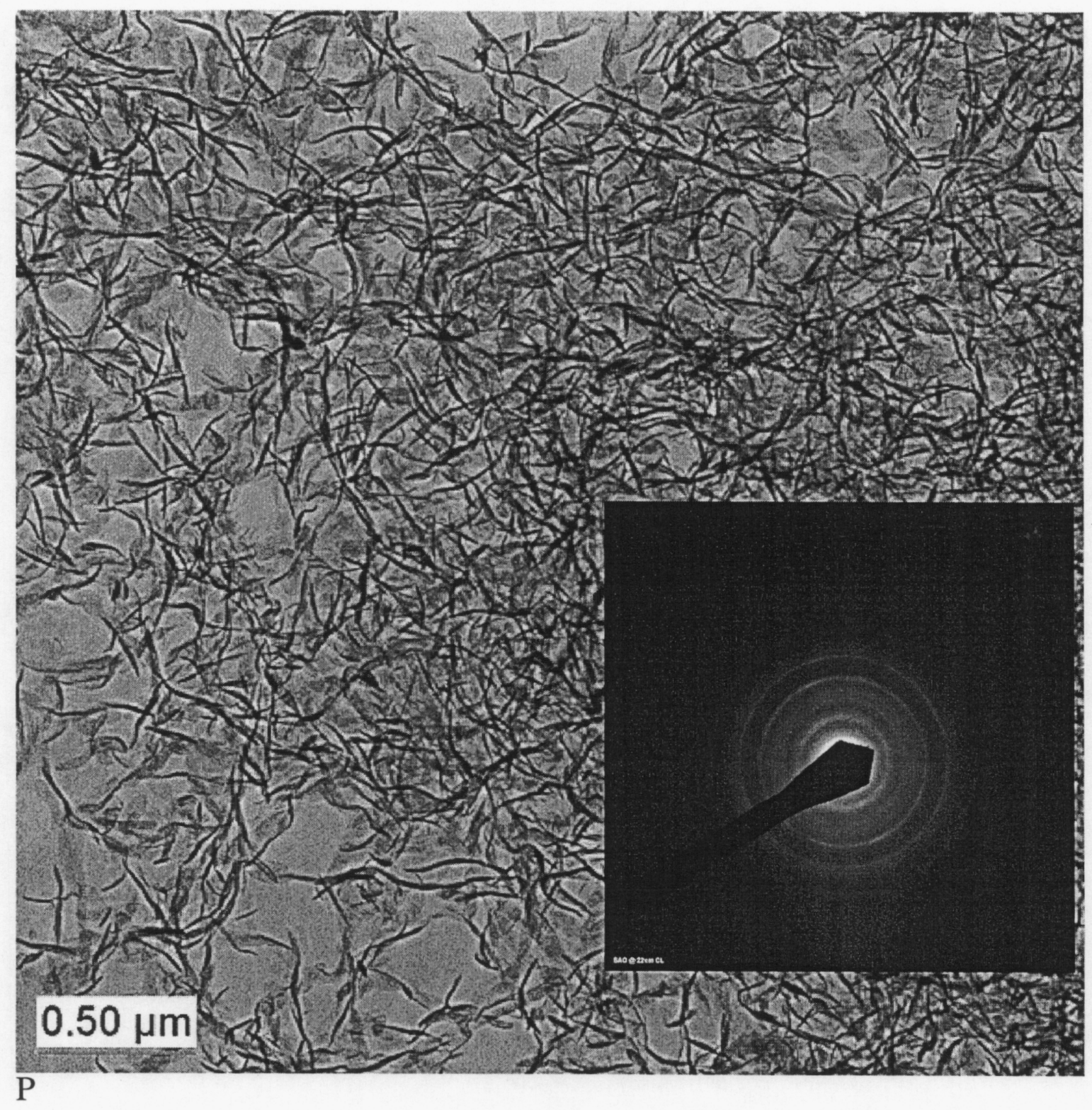

Fig. 2. High resolution transmission electron micrograph of the alumina aerogel showing the acicular, leaf-like nature of the morphology. The insert is the electron diffraction pattern that verifies the existence of an ordered microstructure in the alumina aerogel. 


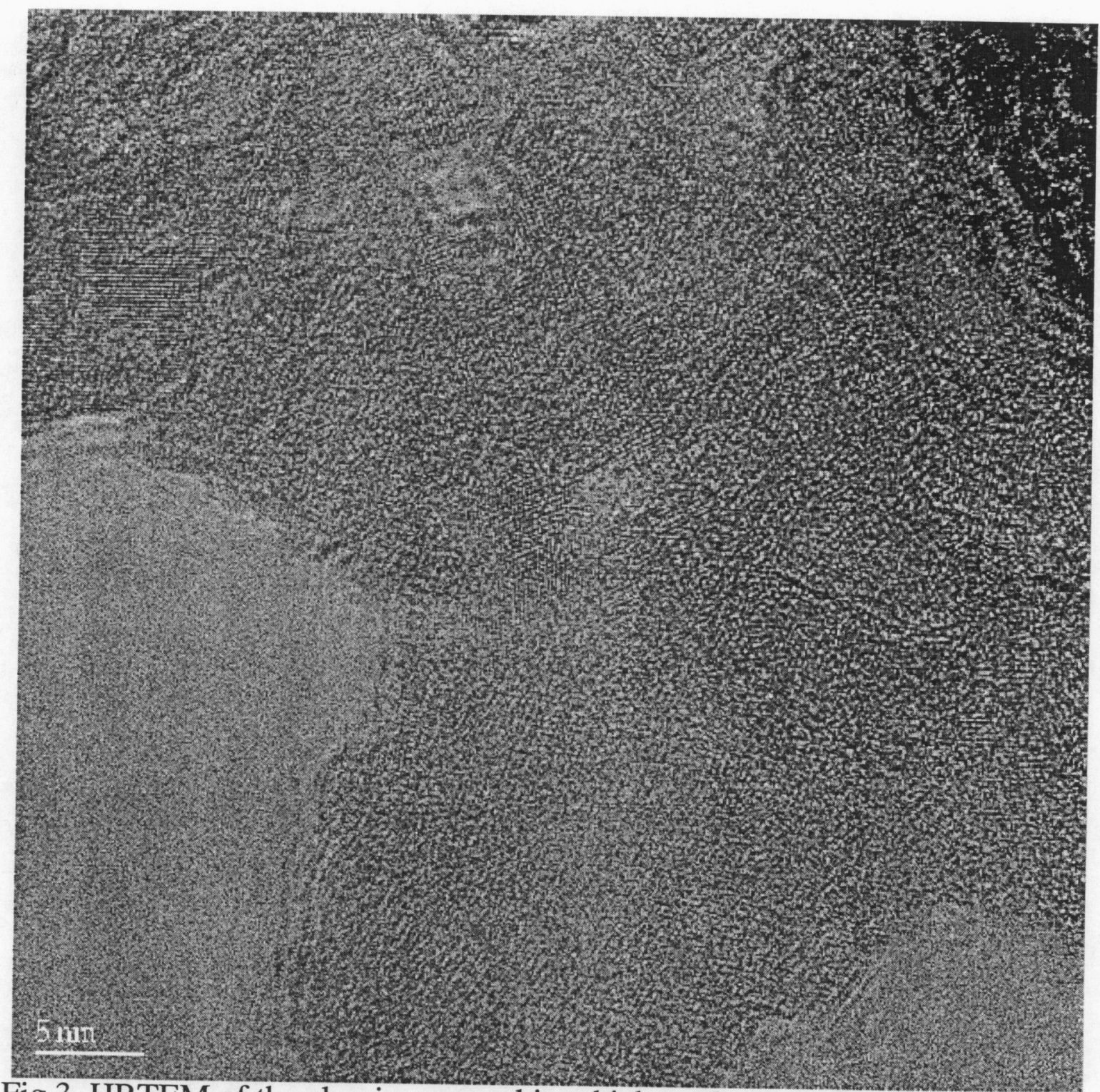

Fig.3. HRTEM of the alumina aerogel in which randomly oriented crystal lattices can be identified. 